\title{
Mortality of first world war military personnel: comparison of two military cohorts
}

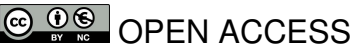

\author{
Nick Wilson associate professor ${ }^{1}$, Christine Clement genealogist ${ }^{2}$, Jennifer A Summers postdoctoral \\ research fellow ${ }^{3}$, John Bannister general practitioner ${ }^{4}$, Glyn Harper professor ${ }^{5}$
}

'Department of Public Health, University of Otago, Wellington, New Zealand; ${ }^{2} 321$ Te Matai Rd, Te Puke, New Zealand; ${ }^{3}$ Division of Health and Social Care Research, King's College London, UK; ${ }^{4}$ Queen Street Medical Practice, Wairoa, New Zealand; ${ }^{5}$ Massey University, Palmerston North, New Zealand

\begin{abstract}
Objective To identify the impact of the first world war on the lifespan of participating military personnel (including in veterans who survived the war)

Design Comparison of two cohorts of military personnel, followed to death.

Setting Military personnel leaving New Zealand to participate in the first world war.

Participants From a dataset of the New Zealand Expeditionary Forces, we randomly selected participants who embarked on troopships in 1914 and a comparison non-combat cohort who departed on troopships in late 1918 (350 in each group).

Main outcome measures Lifespan based on dates of birth and death from a range of sources (such as individual military files and an official database of birth and death records).

Results A quarter of the 1914 cohort died during the war, with deaths from injury predominating (94\%) over deaths from disease $(6 \%)$. This cohort had a significantly shorter lifespan than the late 1918 "non-combat" cohort, with median ages of death being 65.9 versus 74.2 , respectively (a difference of 8.3 years shown also in Kaplan-Meier survival curves, $\log$ rank $\mathrm{P}<0.001)$. The difference for the lifespan of veterans in the postwar period was more modest, with median ages of death being 72.6 versus 74.3 , respectively (a difference of 1.7 years, log rank $P=0.043$ ). There was no evidence for differences between the cohorts in terms of occupational class, based on occupation at enlistment.

Conclusions Military personnel going to the first world war in 1914 from New Zealand lost around eight years of life (relative to a comparable military cohort). In the postwar period they continued to have an increased risk of premature death.
\end{abstract}

\section{Introduction}

Participation in armed conflict by military personnel poses obvious risks of premature death from violent injury. In the first world war other causes of death included deaths from chemical weapons, unintentional injuries (such as from training incidents), hypothermia, suicide, and various infectious diseases, ${ }^{1}$ including malaria ${ }^{2}$ and pandemic influenza. ${ }^{3}$ While war related death tolls for combatant nations of the first world war have been produced, we have found no estimates for the war related life lost per participating soldier.

We determined this for the military personnel who left for the war in 1914 from one of the participating nations: New Zealand. Our primary comparison group for this analysis was a non-combat cohort of military personnel who left New Zealand for the war in late 1918 but who did not see active combat (because of the relatively sudden and unexpected end to the war). The use of this comparison group allowed for avoidance of the "healthy soldier effect," which is a selection effect analogous to the "healthy worker effect." ${ }^{4}$ Furthermore, by selecting groups that both left New Zealand on troopships, we were able to minimise the role of any "healthy warrior effect." This is an additional selection effect, ${ }^{45}$ whereby within the military those sent to combat zones tend to be healthier than those involved in other military roles (such as administration). We also determined if those going to war in 1914 and who survived it continued to experience premature death in the postwar period (relative to the late 1918 non-combat cohort). Such an impact has not been documented for first world war and yet is plausible given the literature about the long term impacts of combat experience (see appendix). 
To provide some context to the New Zealand war effort, an estimated 100444 military personnel served overseas. ${ }^{6}$ They served mainly on the western front but also in campaigns in Gallipoli and Palestine. ${ }^{7-13}$ An estimated $16.6 \%$ (16 700) died, ${ }^{14}$ at least to the period to Armistice Day (11 November 1918), with others dying subsequently, raising the total to an estimated 18311 (18.2\% of participants) by the end of 1923 .

\section{Methods}

\section{Sample frames for two military cohorts}

Before conducting this study, we calculated the sample size for a difference in Kaplan-Meier curves. This calculation used a hazard ratio of 0.80 , with $80 \%$ power, $\alpha$ of 0.05 , and the probability of survival of 0 . This gave sample sizes of 318 in each group, and we rounded this up to 350 in each group.

The sample frame for the 1914 cohort was all military personnel leaving New Zealand on troopships for the war in 1914 (11336 personnel on 14 troopships based on the Cenotaph database held by Auckland Museum ${ }^{15}$ ). Random numbers were generated to select the sample of 350 in this cohort.

For the 1918 cohort, the random sample $(n=350)$ of non-combat military personnel was drawn from those 5944 personnel listed as being on the 10 troopships leaving for the war in 1918 from 13 June to the last troopship before the war ended on 11 November 1918. That is, the war ended before they had either completed supplementary training in England or had moved into frontline positions.

\section{Demographic comparison of cohorts}

We compared the sociodemographic composition of the 1914 and late 1918 cohorts using an established historical classification of occupational class for New Zealand. ${ }^{16}$ Ethnicity classification was based on a system previously used for similar historical work. ${ }^{17}$

\section{Data for estimates of lifespan}

We identified dates of birth and death for each individual from digitalised and publicly available personal military files for first world war military personnel from Archives New Zealand. ${ }^{18}$ Failing this we also searched the official births, deaths, and marriages (BDM) database ${ }^{19}$ and then conducted other searches (for example, military pension records, obituary records, and genealogical databases).

\section{Cause of death data}

For those who died during the period of the war, we abstracted data on the cause of death from the cenotaph database..$^{15} \mathrm{We}$ also obtained death certificates to explore cause of death among the 1914 cohort for those who died aged under 50 in the postwar period $(\mathrm{n}=31)$.

\section{Statistical analyses}

We calculated Kaplan-Meier curves with censoring for those with missing death data at the time of the last date indicating they were alive in the military files. Survival curves were produced in the $\mathrm{R}$ programming language.

A more detailed description of all the methods is in the appendix.

\section{Results}

Ascertainment of dates of birth was all but complete (only one missing), and dates of death were identified for $98 \%$ (343/350) of the 1914 cohort and 95\% (315/331) of the late 1918 (non-combat) cohort. The two cohorts were fairly comparable, except that those in the 1914 cohort were slightly older in 1914 (differences in medians 2.8 years) (table $\downarrow$ ). There were no significant differences in terms of ethnicity, occupational class, or subsequent participation in the second world war. There was a small but significant difference in participation in the preceding South African War by the 1914 cohort (2.3\% v 0\%).

A key finding was that the 1914 cohort had a significantly shorter lifespan than the late 1918 "non-combat" cohort, with median age of death being 65.9 versus 74.2, respectively (a difference of 8.3 years). Figure 1 shows the associated Kaplan-Meier survival curves $\Downarrow(\log$ rank $\mathrm{P}<0.001)$. Similarly, among those who survived the war, the 1914 veterans had lower survival in the postwar period than the late 1918 cohort (fig $2 \Downarrow$, $\log \operatorname{rank} P=0.043$ ). But the differences for veterans were modest, with median ages of death being 72.6 versus 74.3 , respectively (a difference of 1.7 years). When we considered just the period from 1930, this difference declined further (medians $74.0 v 75.0$, respectively) and was no longer significant. As suggested by figure $3 \Downarrow$, the proportion of deaths in those aged under 60 was higher in the 1914 veterans.

A quarter (24.5\%) of the 1914 cohort died during the war, with deaths from injury predominating (94\%) (see appendix table S1). Six percent died from disease, although deaths from pandemic influenza continued after the end of the war. In the postwar period, the death certificate data for veterans who died relatively early (aged under 50) provide evidence for possible war related causes such as operations on wounds, alcoholism, and suicide (see appendix).

\section{Discussion}

\section{Main findings and interpretation}

The cohort of military personnel who went to war in 1914 had a substantially shorter median lifespan (by around eight years) relative to a comparable non-combat military cohort. As far as we can ascertain, this is the first such estimate for a military population participating in the first world war with this type of a comparison group. It reflects the adverse impact of the rigours of the Gallipoli campaign in $1915^{20}$ and trench warfare on the western front (especially 1916-18). Even so, it is plausible that such estimates would be even higher for the military personnel of some other participating nations that had additional hazards to the New Zealand military personnel. Examples could include where soldiers were exposed to the high mortality battles of 1914 and to outbreaks of typhus and typhoid.

The evidence of persisting higher risk of premature death among New Zealand veterans in the postwar period is also a new finding for this war. This finding is plausible given the high morbidity burden for these veterans as indicated by the ongoing qualification for war pension payments to around a fifth of them by $1936(21 \%, \mathrm{n}=15747$ pensions out of 73707 survivors $) .^{21}$ Indeed, an estimated $40.8 \%$ of the military personnel leaving New Zealand received non-fatal wounds in this war. ${ }^{22}$ Such wounds might have increased the risk of death in subsequent operations and death from cardiovascular disease (see appendix). Wounds causing serious disability, disfigurement, and chronic pain could also have increased the risk of suicide. ${ }^{21}$

Post-traumatic stress disorder is also likely to have contributed to the postwar risk of suicide, given evidence for suicidal ideation among some of these veterans. ${ }^{23}$ Other work has estimated a total of 333 suicides among New Zealand's veterans, 
with higher suicide rates than in civilian men in the same age cohort during the 1920s and subsequent decades. ${ }^{21}$

\section{Study strengths and limitations}

Our study benefited from the use of a comparison non-combat military population that will have minimised both the "healthy soldier" and "healthy warrior" selection effects. Nevertheless, we have identified several limitations with this study, which could still have played a role in generating or reducing differences between the two groups (see appendix for fuller details). One of the factors reducing the differences in lifespan could have been that at enlistment the 1918 cohort might have been slightly less physically and psychologically healthy than the 1914 cohort. This could be because of the introduction of conscription in 1916 and because there had been some lifting of the height and weight restrictions on recruits since 1914. ${ }^{24}$ Nevertheless, the rejection rate seems to have remained high, with a figure for the November 1916 to November 1918 period indicating a $57.6 \%$ rejection rate $(n=77900$ rejected out of $\mathrm{n}=135282$ examined). ${ }^{25}$

In contrast, the 1918 cohort might have benefited from slightly increased life expectancy by being born slightly later than the 1914 cohort (see table $\Downarrow$ ). For example, for a 25 year old New Zealand woman, additional life expectancy rose from an extra 52.7 years in 1914 to an extra 53.9 years in 1918 (that is, 0.3 extra years of life per year, as per online data associated with a Statistics New Zealand study ${ }^{26}$ ). For New Zealand men, the data for life expectancy in this period were influenced by the increased mortality related to the war, but life expectancy still increased overall (the equivalent figures to those for women above are 45.3 and 46.7 years, and a gain of 0.35 extra years of life per year). So it is possible that around 1.0 years (2.8 years [difference in median ages] $\times 0.35$ ) of the difference in lifespan of the two cohorts is attributable to age cohort effects. This still left a gap in differences between median lifespan ( 0.7 years), when we consider veterans in the entire postwar period.

\section{Conclusions}

Military personnel going to the first world war in 1914 from New Zealand lost around eight years of life (relative to a comparable non-combat military cohort). Out of those in this 1914 cohort group who survived the war, its impact continued to lower their lifespan in subsequent years.

We thank James Stanley for statistical support and for Archives New Zealand for digitalising military files on request.

Contributors: NW designed the study. NW, JS, and GH examined historical literature. The data were extracted by CC, NW, JS, and JB. NW analysed the data. All authors interpreted the data and contributed to writing the manuscript. NW is guarantor.

Funding: This study received partial funding from the University of Otago and Massey University for purchase of death certificate data. JS was supported by the NIHR Biomedical Research Centre based at Guy's and St Thomas' NHS Foundation Trust and King's College London.

Competing interests: All authors have completed the ICMJE uniform disclosure form at www.icmje.org/coi_disclosure.pdf and declare: no support from any organisation for the submitted work; no financial relationships with any organisations that might have an interest in the submitted work in the previous three years; no other relationships or activities that could appear to have influenced the submitted work. Ethical approval: Not required.

Data sharing: Data sharing of Excel databases related to these two cohorts are available from the corresponding author.

Transparency: The lead author (the manuscript's guarantor) affirms that this manuscript is an honest, accurate, and transparent account of the study being reported; that no important aspects of the study have been omitted; and that any discrepancies from the study as planned (and, if relevant, registered) have been explained.

1 Carbery A. The New Zealand Medical Service in the Great War 1914-1918. Whitcombe and Tombs, 1924. www.nzetc.org/tm/scholarly/tei-WH1-Medi-t1-front-d5.html.

2 Shanks GD. Simultaneous epidemics of influenza and malaria in the Australian Army in Palestine in 1918. Med J Aust 2009;191:654-7.

3 Byerly CR. The US military and the influenza pandemic of 1918-1919. Public Health Rep 2010;125(suppl 3):82-91.

4 McLaughlin R, Nielsen L, Waller M. An evaluation of the effect of military service on mortality: quantifying the healthy soldier effect. Ann Epidemiol 2008;18:928-36.

5 Wilson J, Jones M, Fear NT, Hull L, Hotopf M, Wessely S, et al. Is previous psychological health associated with the likelihood of Iraq War deployment? An investigation of the "healthy warrior effect". Am J Epidemiol 2009;169:1362-9.

6 Crawford J, McGibbon IE. New Zealand's Great War: New Zealand, the Allies, and the First World War. Exisle Publishing, 2007.

7 Harper GJ. Letters from Gallipoli: New Zealand soldiers write home. Auckland University Press, 2011.

8 Harper G. Dark journey. HarperCollins, 2007.

9 Fenton D. New Zealand and the First World War 1914-1919. Penguin Books, 2013.

10 Kinloch T. Devils on horses. Exisle Press, 2007.

11 Powles CG. The New Zealanders in Sinai and Palestine. Whitcombe and Tombs, 1922.

12 Stewart H. The New Zealand Division 1916-19. A Popular History Based on Officia Records. Whitcombe and Tombs, 1921.

13 Waite F. The New Zealanders at Gallipoli. Whitcombe and Tombs, 1921.

14 Wilson N, Summers JA, Baker MG, Thomson G, Harper G. Fatal injury epidemiology among the New Zealand military forces in the First World War. N Z Med J 2013;126:13-25.

15 Auckland War Memorial Museum. Cenotaph database.http://muse.aucklandmuseum.com databases/Cenotaph/locations.aspx?

16 Olssen E, Hickey M. Class and occupation: the New Zealand reality. Otago University Press, 2005.

17 Wilson N, Telfar Barnard L, Summers J, Shanks G, Baker M. Differential mortality by ethnicity in 3 influenza pandemics over a century, New Zealand. Emerg Infect Dis 2012;18:71-7.

18 New Zealand Government. Archway Archives New Zealand.www.archway.archives.govt. $\mathrm{nz}$.

19 Births Deaths and Marriages New Zealand. Births, deaths and marriages historical records. 2012. http://bdmhistoricalrecords.identityservices.govt.nz/Home/.

20 Wilson N, Nghiem N, Summers J, Carter M-A, Harper G. A nutritional analysis of New Zealand military food rations at Gallipoli in 1915: likely contribution to scurvy and other nutrient deficiency disorders. N Z Med J 2013;126:1-18.

21 Weaver JC. Sorrows of a century: interpreting suicide in New Zealand, 1900-2000. Bridget Williams Books, 2014

22 Ministry for Culture and Heritage. New Zealand and the first world war. www.nzhistory. net.nz/war/first-world-war-overview/introduction.

23 Chisholm P, Rhind SD. Some aspects of post-war psycho-neurosis and their treatment at the Queen Mary Hospital, Hanmer Springs. N Z Med J 1920;19:222-9.

24 Baker P. King and Country. New Zealanders, conscription and the Great War. Auckland University Press, 1988:110-5.

25 Territorial military training and physical efficiency. N Z Med J 1920;19:245-6.

26 Statistics New Zealand. A history of survival in New Zealand: cohort life tables 1876-2004. Statistics New Zealand, 2006. www.stats.govt.nz/browse_for_stats/health/life_expectancy/ cohort-life-tables.aspx

Accepted: 04 November 2014

\section{Cite this as: BMJ 2014;349:97168}

This is an Open Access article distributed in accordance with the Creative Commons Attribution Non Commercial (CC BY-NC 4.0) license, which permits others to distribute, remix, adapt, build upon this work non-commercially, and license their derivative works on different terms, provided the original work is properly cited and the use is non-commercial. See: http://creativecommons.org/licenses/by-nc/4.0/. 


\section{What is already known on this topic}

While participation in armed conflict by military personnel poses obvious risks of premature death from violent injury, the extent to which life expectancy was reduced for any military force in the first world war has not been quantified

The impact of war exposure on veteran survival is more difficult to determine because of the "healthy soldier" selection effect

\section{What this study adds}

Soldiers who left for the first world war from New Zealand in 1914 lost around eight years of life (relative to a comparable non-combat military cohort)

Similarly, among survivors of the war, the 1914 veterans lived an average of 1.7 fewer years than non-combat veterans (comparing median ages of death)

This war had a major impact on the health of participating soldiers, in whom an additional burden of premature death persisted into the postwar period

\section{Table}

\begin{tabular}{|c|c|c|c|}
\hline Characteristic & 1914 cohort $^{*}(n=350)$ & 1918 (non-combat) cohort $\dagger(n=330)$ & $P$ value for differences \\
\hline \multicolumn{4}{|l|}{ Birth year and age: } \\
\hline Median year of birth (IQR) & $1890(1886-94)$ & $1893(1866-98)$ & - \\
\hline Range of birth years & $1863-97$ & $1862-99$ & - \\
\hline Median (IQR) age in mid-1914 (years) & $23.9(21.4-28.2)$ & $21.1(16.6-28.9)$ & $<0.001$ \\
\hline Age range in 1914 (years) & $16.6-51.2$ & $14.8-52.0$ & - \\
\hline \multicolumn{4}{|l|}{ Ethnicity: } \\
\hline $\begin{array}{l}\text { Māori names, or other information to suggest Māori } \\
\text { ethnicity }\end{array}$ & $2(0.57)$ & $4(1.21)$ & 0.37 \\
\hline \multicolumn{4}{|l|}{ Occupational class: } \\
\hline Highest: 1-2 (for example, doctor) & $15(4.3)$ & $15(4.6)$ & 0.64 \\
\hline 3-4 (for example, school teacher, farmer) & $76(21.7)$ & $73(22.3)$ & \\
\hline 5-6 (for example, ironworker, clerk) & $60(17.2)$ & $54(16.5)$ & \\
\hline 7-8 (for example, carpenter, driver) & $101(28.9)$ & $98(30.0)$ & \\
\hline Lowest: 9 (for example, labourer, farm hand) & $962(7.4)$ & $87(26.6)$ & \\
\hline Median (IQR) occupational class score & $7.0(4.0-9.0)$ & $7.0(4.5-9.0)$ & 0.99 \\
\hline \multicolumn{4}{|l|}{ Other details: } \\
\hline $\begin{array}{l}\text { Also were in New Zealand military forces in South } \\
\text { African War (1899-1902) }\end{array}$ & $8(2.3)$ & 0 & 0.006 \\
\hline $\begin{array}{l}\text { Also were in New Zealand military forces in second } \\
\text { world war (1939-45)‡ }\end{array}$ & $47(18.0)$ & $40(12.3)$ & 0.54 \\
\hline
\end{tabular}

IQR=interquartile range.

*Virtually all volunteers with some military professionals ( $n=9$ in this sample).

†Mix of volunteers, conscripts, and military professionals ( $n=1$ in this sample). Though data on conscription status was rare in personal military files, an estimated $31 \%$ of New Zealand men who participated in war were conscripts. From the randomly selected 350 individuals, exclusions included women ( $n=2$ ); those with Pacific Island ethnicity from outside of New Zealand (for instance, from the Cook Islands) $(n=5)$; those who had previously left New Zealand on a troopship in earlier years.

$\ddagger$ Numbers are from denominator populations of surviving veterans of first world war of $n=214$ and $n=285$, for 1914 and 1918 cohorts, respectively. None of these participants in this subsequent world war were killed in this war. 


\section{Figures}

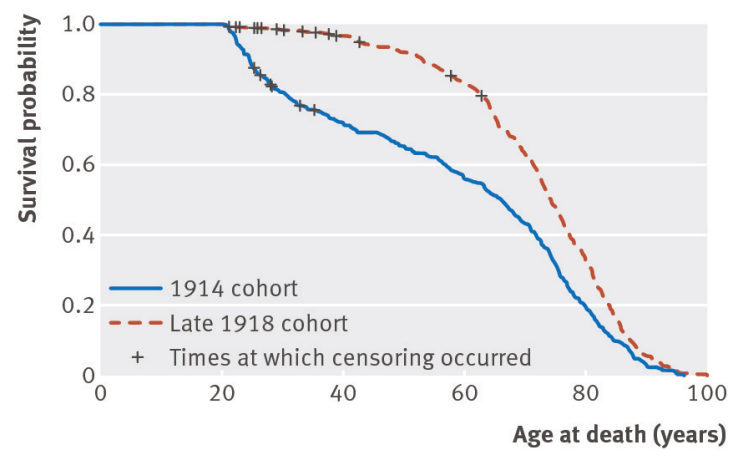

Fig 1 Kaplan-Meier survival curves for 1914 and 1918 "non-combat" military cohorts

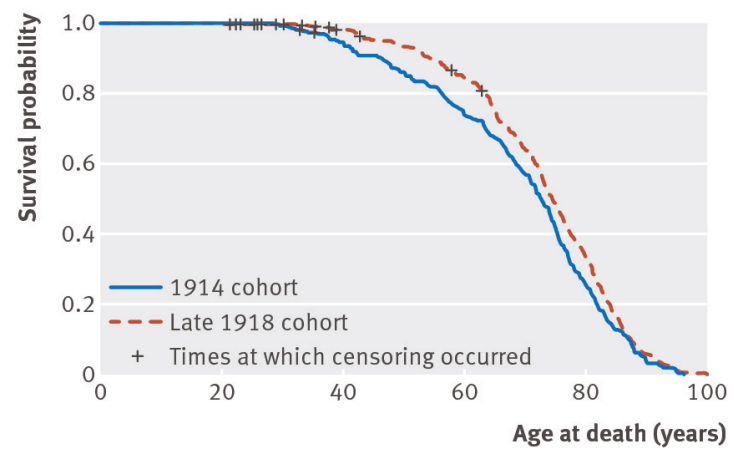

Fig 2 Kaplan-Meier survival curves for veterans who survived first world war from 1914 and late 1918 "non-combat" military cohorts

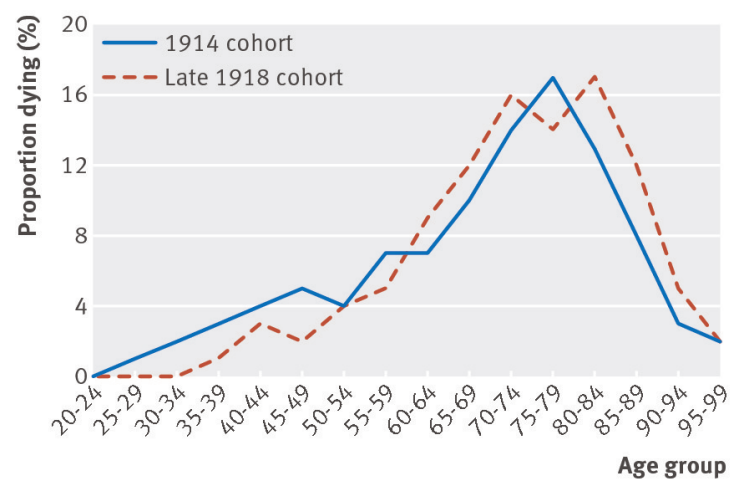

Fig 3 Proportion of deaths at different ages among veterans of both cohorts who survived first world war ( $n=259$ in 1914 cohort and $n=310$ in late 1918 cohort, excluding censored deaths) 